\title{
/Article
}

\section{Analyzing Retirement Withdrawal Strategies}

\author{
Robert J. Rietz (MAAA, FCA)*, Tim Blumenschein, Spencer Crough, Albert Cohen (PhD) \\ *Author to whom correspondence should be addressed; E-mail: dbactuary@ hotmail.com; \\ Tel:+1-313-530-3071. \\ Tim Blumenschein; blumens6@msu.edu \\ Spencer Crough; croughsp@msu.edu \\ Albert Cohen: acohen@msu.edu \\ Academic Editor: \\ Received:
}

Abstract: An optimal withdrawal strategy beginning at age 65 provides a lifetime income from a portfolio, adjusted annually for inflation, while reducing the probability of living in financial ruin to an acceptable level. This paper analyzes the probability of living in financial ruin, potentially for multiple years, rather than just the event of ruin. A stochastic Excel model was developed to simulate the effect of varying investment returns on a portfolio with two asset classes; large company stocks and long-term government bonds. A stochastic model is also applied to retiree mortality.

The following variables were analyzed to determine their relative impact on withdrawal strategies:

- Withdrawing a constant percentage of the portfolio,

- Gender,

- Initial asset allocation,

- Asset allocation rebalancing methods, and

- Low investment return environments.

For both genders and most withdrawal rates, an approximately equal initial asset allocation of stocks and bonds, combined with a level rebalancing function, provided the lowest probability of living in financial ruin.

Because each investment return followed its own probability distribution function, some retirees experienced financial ruin even in the most conservative simulations.

Keywords: financial ruin, withdrawal strategy, asset allocation, rebalancing method, portfolio 


\section{Introduction:}

1.1 Increase in the Role of Defined Contribution Plans: The traditional paradigm of American retirement planning has been Social Security, an employer-provided pension and private savings, known as the three-legged stool. However, employer-provided pensions have been decreasing in significance as plan sponsors have frozen participants' accrued benefits, frozen their plans to new entrants and/or terminated their defined benefit plans. Figure 1.1 (below) from a recent GAO report shows the amount of retirement assets in defined benefit pension plans over time, compared to the amount of retirement assets in defined contribution plans (401(k) plans, 403(b) plans, 457 plans and IRAs) ${ }^{i}$. While the amount of defined benefit assets roughly equaled the amount of defined contribution assets in the mid-1980s, today defined contribution assets are over four times the amount of defined benefit assets.

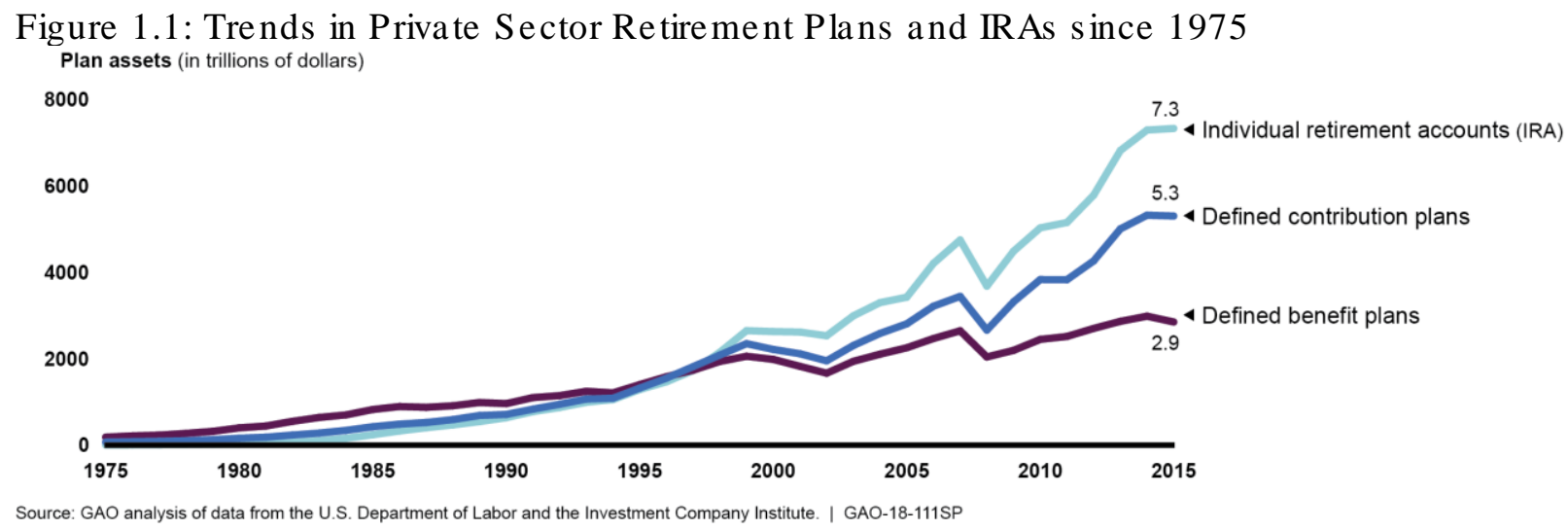

Many employers still provide retirement benefits to their employees, though today it is more often in the form of a defined contribution plan than a defined benefit plan. Because defined contribution plans typically pay a lump sum instead of a lifetime pension, today's retirees are faced with managing a large amount of money that must last for their lifetime. These retirees have now assumed investment risk, longevity risk and inflation risk as well as other aging risks. ${ }^{\text {ii }}$

1.2 Increased Longevity Risk: Longevity risk for the individual can be defined as the extent to which an individual's actual life span significantly exceeds his or her life expectancy. ${ }^{\text {iii }}$ The financial cost of longevity risk is that either individuals will outlive their retirement savings or alternatively, they will underspend their savings, leading to a lower income during retirement and an unintentional bequest on death. ${ }^{\text {iv }}$ For example, a retiree who made withdrawals of $1 \%$ of her initial portfolio, adjusted annually for inflation, would almost certainly avoid financial ruin. However, these withdrawal amounts might not be adequate for maintaining the retiree's pre-retirement standard of living, unless the portfolio was three or four times larger than a portfolio that would be expected to sustain a $3 \%$ or $4 \%$ withdrawal rate. 
Individuals who base their retirement planning on life expectancies are accepting a substantial longevity risk. Research over the last 50 years or more has established that longevity in the United States for someone age 65 has been increasing at about the rate of one year every decade. $^{\mathrm{v}}$ The RP-2014 Mortality Table ${ }^{\mathrm{vi}}$ projected by scale MP-2016 ${ }^{\mathrm{vii}}$ indicates that a male age 65 in 2018 has a $50 \%$ probability of living to age 86 and a $25 \%$ probability of living to age 92 . The corresponding ages for a female age 65 in 2018 are 88 and 94. These probabilities, and other probabilities, are displayed on Chart 1.2.

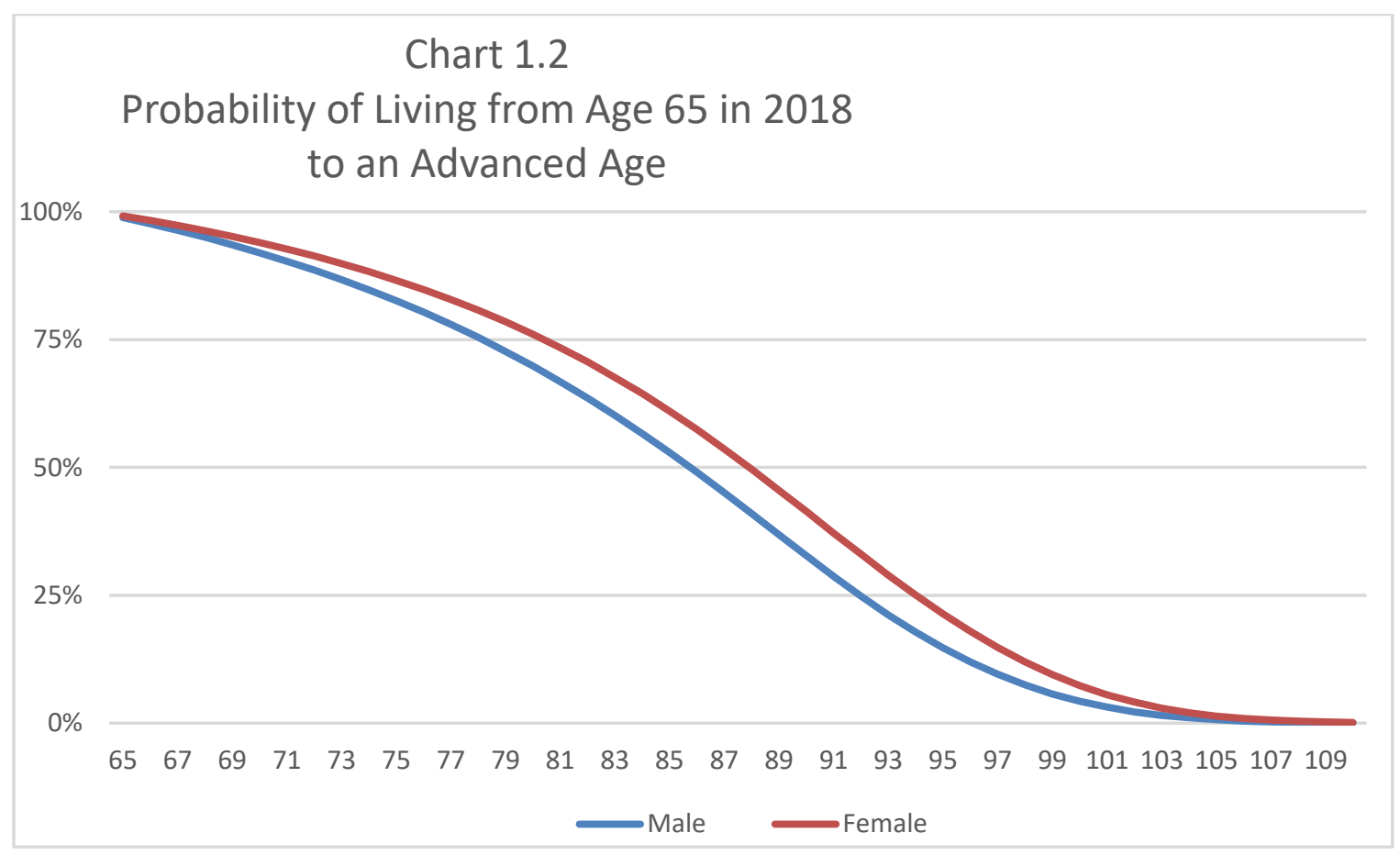

RP-2014 Mortality with Generational Improvement Using Scale MB-2016

Retirees are becoming aware of the significant longevity risk they are facing. A survey of retirees by Allianz Life Insurance Company of North America found that " $61 \%$ of the respondents said they were more scared of outliving their assets than they were of dying."viii

1.3 Financial Ruin in Retirement: The topic of avoiding financial ruin in retirement has been studied by several researchers. William Bengen published his 4\% Rule in 1994, claiming that this method provides the maximum withdrawal rate while ensuring portfolio solvency in any historic rolling 33-year period. ${ }^{\text {ix }}$ The article also discussed asset allocation, and found that the optimum stock allocation was between $50 \%$ and $75 \%$. The $4 \%$ Rule has been a classic rule of thumb for financial planners ever since his article was published. 
However, additional research by Finke, Pfau \& Blanchett determined that the 4\% Rule was not a safe withdrawal rate in a low investment return environment. ${ }^{x}$ They suggested that safer withdrawal rates in the current low investment return environment were in the range of $2.0 \%$ to $2.5 \%$, depending on the asset allocation and the withdrawal period. The authors also found that a stock allocation between $50 \%$ and $75 \%$ minimized financial ruin using a $3 \%$ withdrawal rate. Higher withdrawal rates required $100 \%$ stock allocation to minimize portfolio failure, but failure rates exceeded $40 \%$ for these higher withdrawal rates.

Both the Bengen paper and the Finke, Pfau \& Blanchett paper adjusted the initial withdrawal amount by inflation to maintain a constant real withdrawal amount.

Another paper ${ }^{\mathrm{xi}}$ by Kristen Moore and Virginia Young developed a theoretical optimal investment strategy and a practical near-optimal investment strategy, both designed to minimize the probability of financial ruin in retirement. That paper focused on rebalancing the portfolio from a risky asset to a riskless asset as the retiree aged. This paper builds on the practical rebalancing strategy and measures the probability of financial ruin using a model that applies stochastic methods for both annual investment returns and mortality.

Much prior research analyzed financial ruin as a terminal event. That is, the research analyzed when the retiree's portfolio was exhausted. This paper measures financial ruin in a slightly different manner. It analyzes the probability of exhausting the retiree's portfolio while the retiree is still alive, and potentially living multiple years thereafter. This paper's model includes the length of time that retirees live after their portfolios are exhausted in its measurement of financial ruin. A retiree who depletes his portfolio must lower his desired standard of living, even if a Social Security benefit and defined benefit pension still remain. This paper considers such a reduced standard of living as living in "poverty", a word that this paper will use in place of "financial ruin".

This paper defines a near optimal withdrawal strategy as one that supports a desired lifetime income, net of Social Security and defined benefit pensions, from a portfolio at age 65, adjusted for inflation, that reduces the probability of exhausting the portfolio while the retiree is alive to an acceptable level.

\section{Results:}

There were six primary findings from an analysis of the model's output:

1. The lower the withdrawal rate as a percent of the initial portfolio, the lower the probability of living in poverty.

2. There is a modest difference in the probability of living in poverty between genders for the same withdrawal percentage, asset allocation and rebalancing method. 
3. Both overly aggressive initial asset allocations, as well as overly conservative initial asset allocations, had higher probabilities of living in poverty than initial asset allocations that were more balanced.

4. Rebalancing methods had little impact on the probability of living in poverty, with level annual rebalancing providing a modest decrease in the probability of ruin.

5. A low investment return environment substantially increases the probability of living in poverty unless the retiree reduces the withdrawal rate. In a low return environment, such as the current environment, utilizing the $4 \%$ Rule produces a substantially higher probability of living in poverty.

6. Because investment returns followed a probability distribution function, some unfortunate retirees experienced living in poverty even in the most conservative simulations.

The probability of living in poverty from ages 65 to 74 is less than $1 \%$ for almost all of the situations studied, and is therefore not shown in the graphs in this paper.

The base case used an initial asset allocation of $60 \%$ large company stocks and $40 \%$ long-term government bonds, rebalancing each year to maintain that allocation, and a $2.75 \%$ constant inflation rate. Chart 2.1 shows the probability of retirees living in poverty at each age while withdrawing $4.0 \%$ of the initial portfolio each year, adjusted for $2.75 \%$ annual inflation. About $1 \%$ of the original 10,000 male retirees and 10,000 female retirees were living in poverty in their late 80s and thereafter. Chart 2.1 also displays the percentage of surviving retirees who are living in poverty. In this simulation, about $4 \%$ of surviving retirees (both genders) were living in poverty at age 95 , while the percentage of females living in poverty after that age continued to increase.

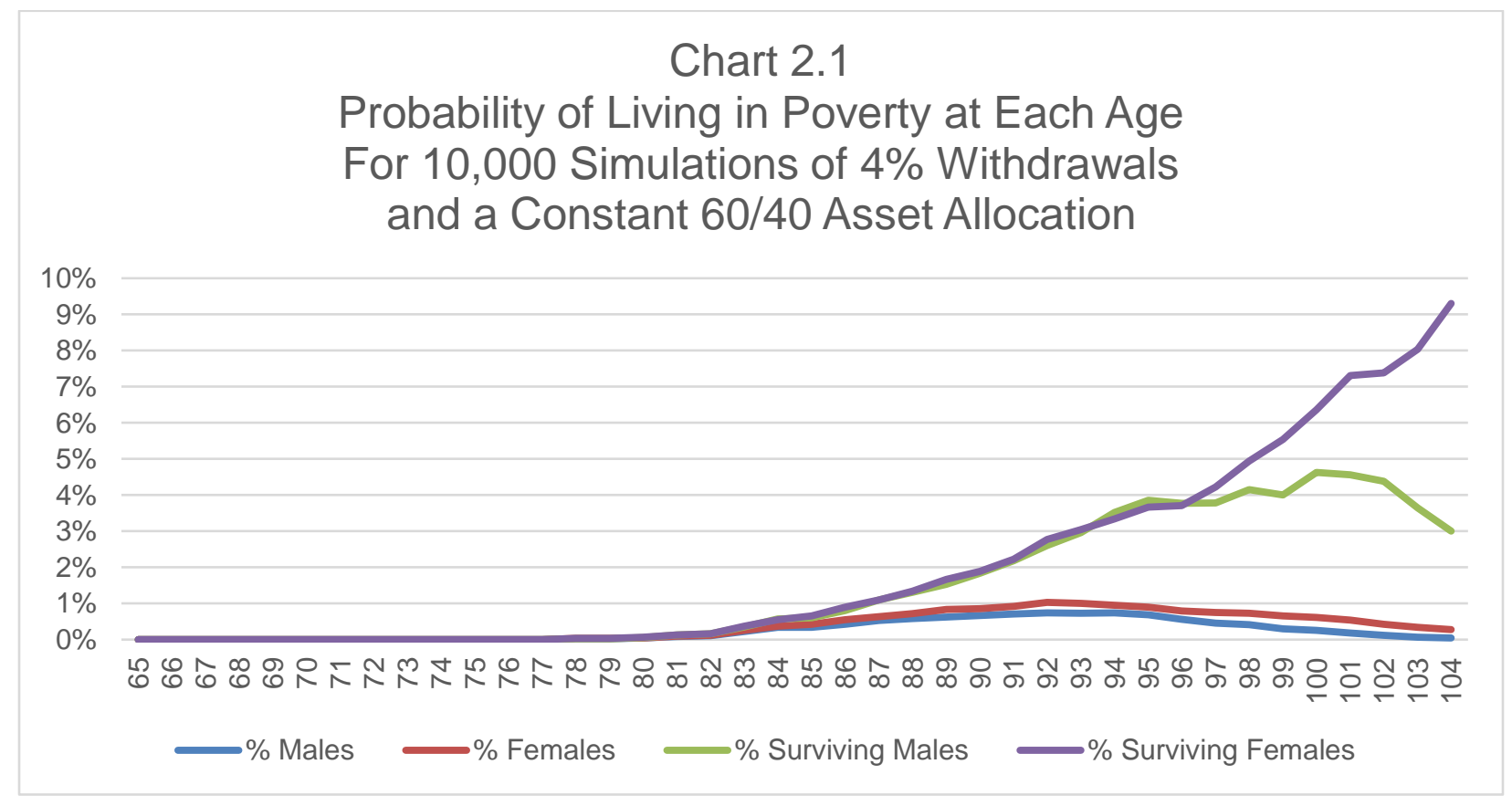


2.1. Initial Withdrawal Rates: Chart 2.2 shows the dramatic differences in the probabilities of living in poverty depending on withdrawal rate and gender. Increasing the withdrawal rate from $3 \%$ to $4 \%$ modestly increases the probability of living in poverty for both genders. However, Increasing the withdrawal rate to $5 \%$ increases the probability of living in poverty substantially, particularly for extreme initial asset allocations. The impact of rebalancing initial asset allocations is discussed in Section 2.4.

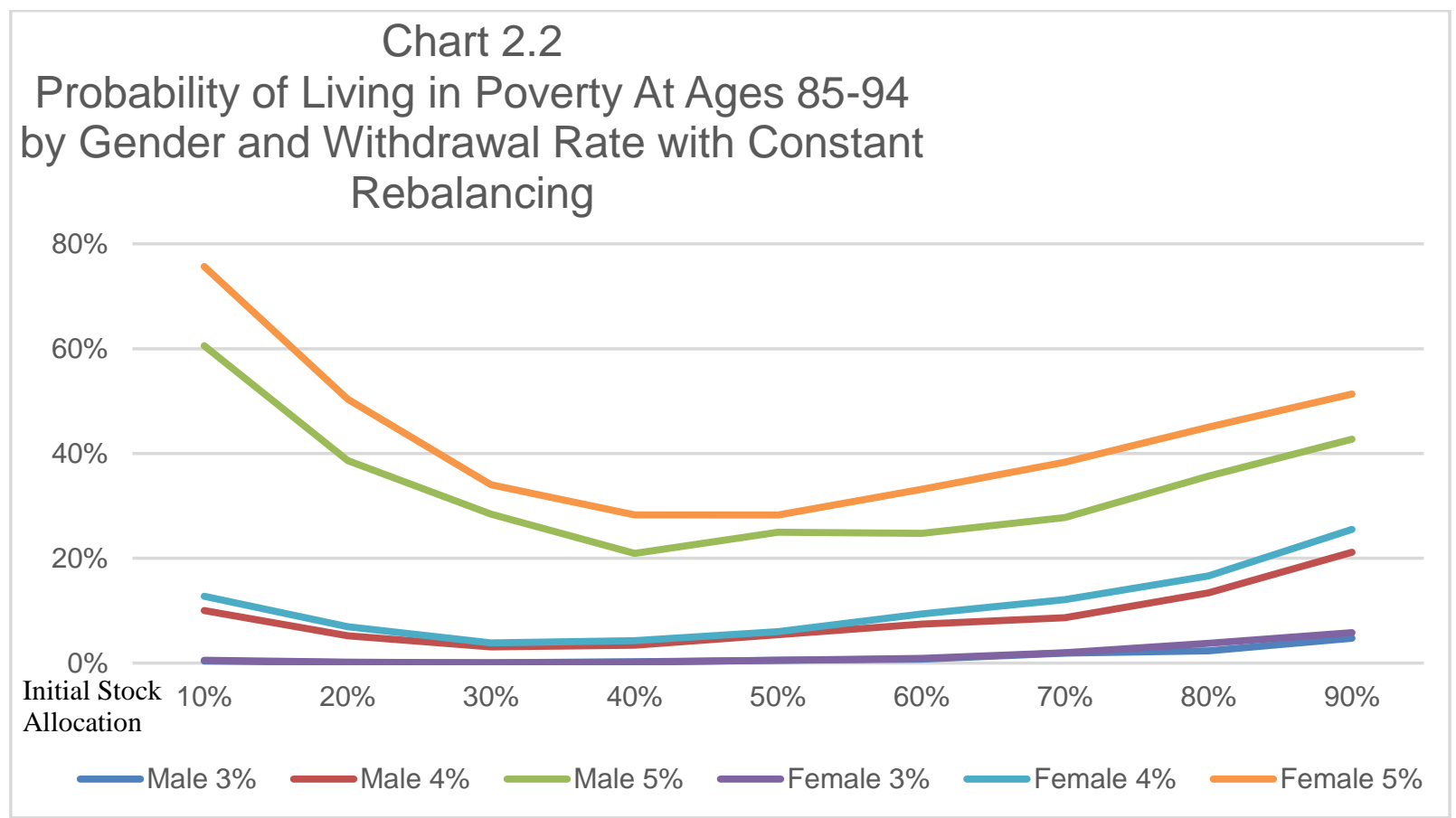

2.2. Gender: It's well established that females experience better mortality than males at the same ages. Chart 2.1 (above) shows a small, but definite, increase in females living in poverty beginning around age 81 compared to males living in poverty for the base case, with all other variables being equal. This difference was observed in the other analyses done for this paper. The chart suggests that some males and females were approaching financial ruin in their late 70s, but males were more likely to die before reaching financial ruin than females. Similarly, males living in poverty were again more likely to die than females living in poverty. The combined effect is that slightly more females than males are projected to be living in poverty for any combination of variables.

A comparison of annuity certain values illustrates this finding. Life expectancy for females and males at age 65 are approximately 23 years and 21 years respectively. Using a $6.0 \%$ interest rate, the ratio of an annuity certain for 23 years to an annuity certain for 21 years is around $104.5 \%$. A similar relationship holds for life annuities, using the mortality assumption in this paper. The ra- 
tio of a female life annuity at age 65 to a male life annuity at age 65 is around $105.5 \%$. These ratios suggest that females require a portfolio at age 65 very roughly about $5 \%$ larger than a male's portfolio, for the same withdrawal amount with all other variables being equal.

This paper focuses only on the spending phase during retirement. The authors acknowledge that there are differences in each gender's respective ability to accumulate equivalent portfolios before retirement due to differing work patterns and income inequality.

2.3. Initial Asset Allocation: The initial asset allocation has a large impact of the number of retirees that live in poverty as they age.

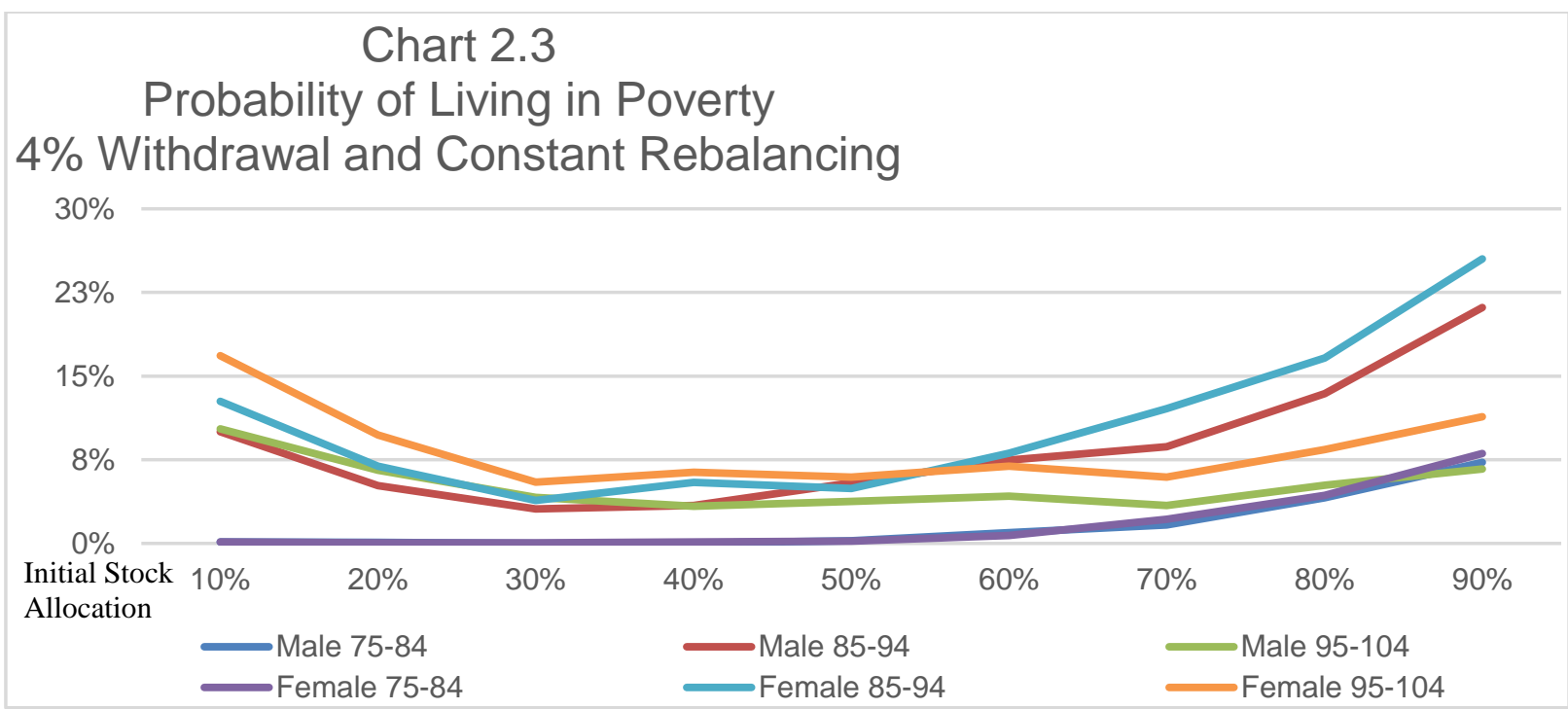

The graphs in Chart 2.3 shows that asset allocation versus the probability of living in poverty is concave, with about a $30 \%$ to $60 \%$ initial asset allocation in stocks being optimal. The concavity of the graph is due to the rate of return and volatility of the portfolios. When starting with very risk-averse portfolios, retirees are sacrificing higher rates of return for safety, although they are not earning sufficiently high rates of return to prevent living in poverty. When investors start with a very aggressive portfolio they may earn higher rates of return, however the increased volatility also exposes them to greater losses. If a retiree is very unfortunate, one of these decreases can destroy a large proportion of their portfolio, particularly if the loss occurs relatively early in retirement. Diversification of risk is a large factor in the prevention of living in poverty.

2.4 Rebalancing Methods: The preceding analyses utilized a constant asset allocation, regardless of the investment performance of each asset class. For example, if stocks outperformed bonds, the portfolio was rebalanced each year so that the initial asset allocation was maintained. 
The model utilized three rebalancing methods in each scenario; constant rebalancing, level rebalancing and geometric rebalancing. With constant rebalancing, the initial asset allocation was held constant throughout each simulated retiree's lifetime as explained previously. Level rebalancing uniformly shifted the asset allocation each year from stocks into bonds over 40 years. The percentage of assets allocated to stocks each year depended on the initial asset allocation, and was calculated so that at age 104, the assets of each simulated retiree would be invested entirely in bonds. For example, this level rebalancing method for a 60/40 initial asset allocation would result in a 58.5/41.5 asset allocation in the second year. Geometric rebalancing was similarly calculated based on the initial asset allocation, except that the percentage of stocks shifted each year was calculated as the annual percentage of the portfolio necessary to shift to bonds to have $100 \%$ of the assets invested in bonds by age 104 .

Rebalancing appeared to have only a slight impact on the probability of living in poverty, as displayed in Chart 2.4. Level rebalancing had the most impact, albeit slight, while geometric rebalancing had less impact. Constant rebalancing generally provided the highest probability of living in poverty at all initial asset allocations, although the impact was also slight.

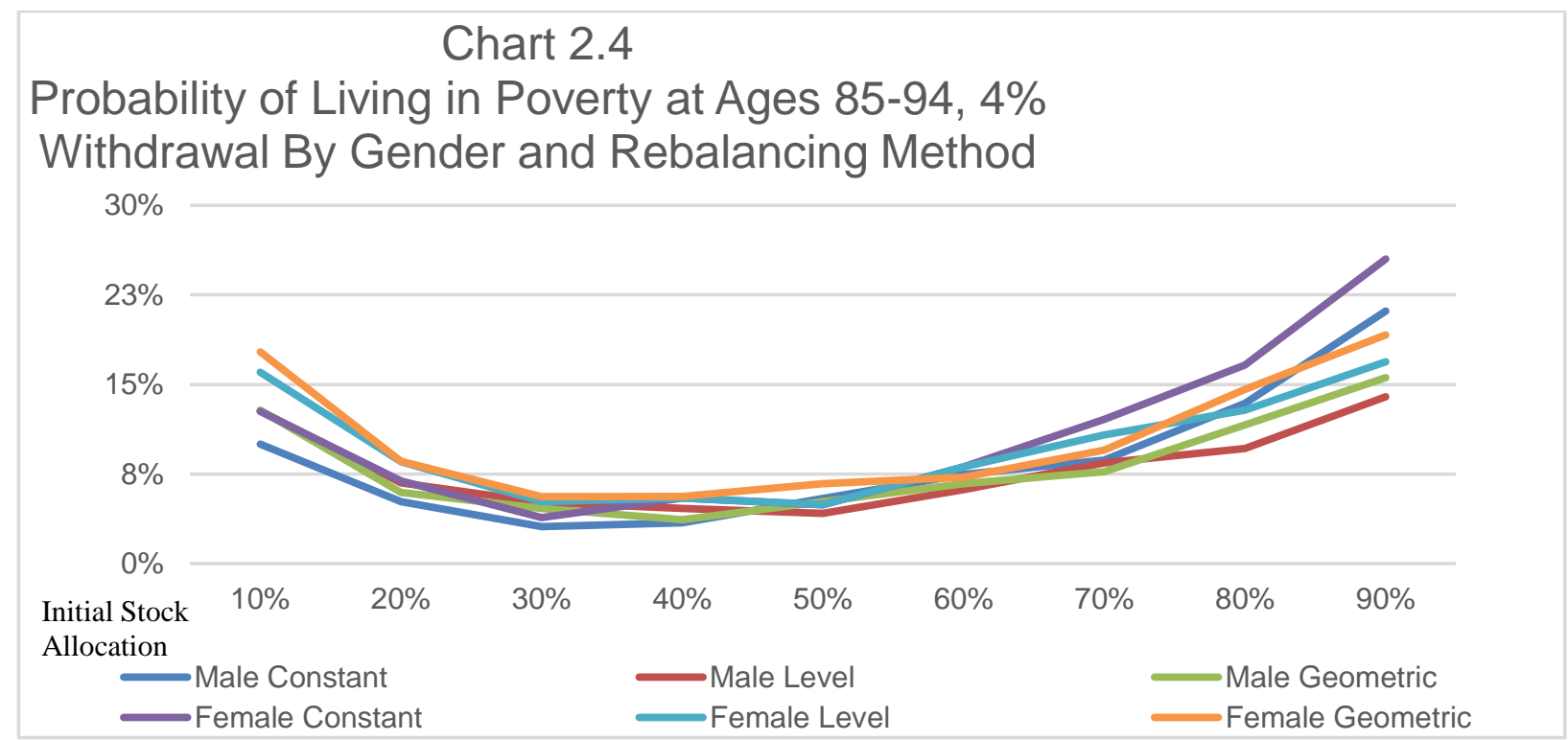

2.5 Low Investment Return Environment: To reflect the current low investment return environment, the model incorporated an arbitrary damper to reduce a portfolio's rate of return. Reducing rates of return had a devastating result on retirees' portfolios, which resulted in a significant increase in the probability of living in financial ruin. Both Chart 2.5.1 and Chart 2.5.2 display the results of a 3.0\% withdrawal strategy with constant asset allocation, but Chart 2.5.2 has a 1.5\% damper. The results are even more dramatic with a $3 \%$ damper (results not graphed.) 


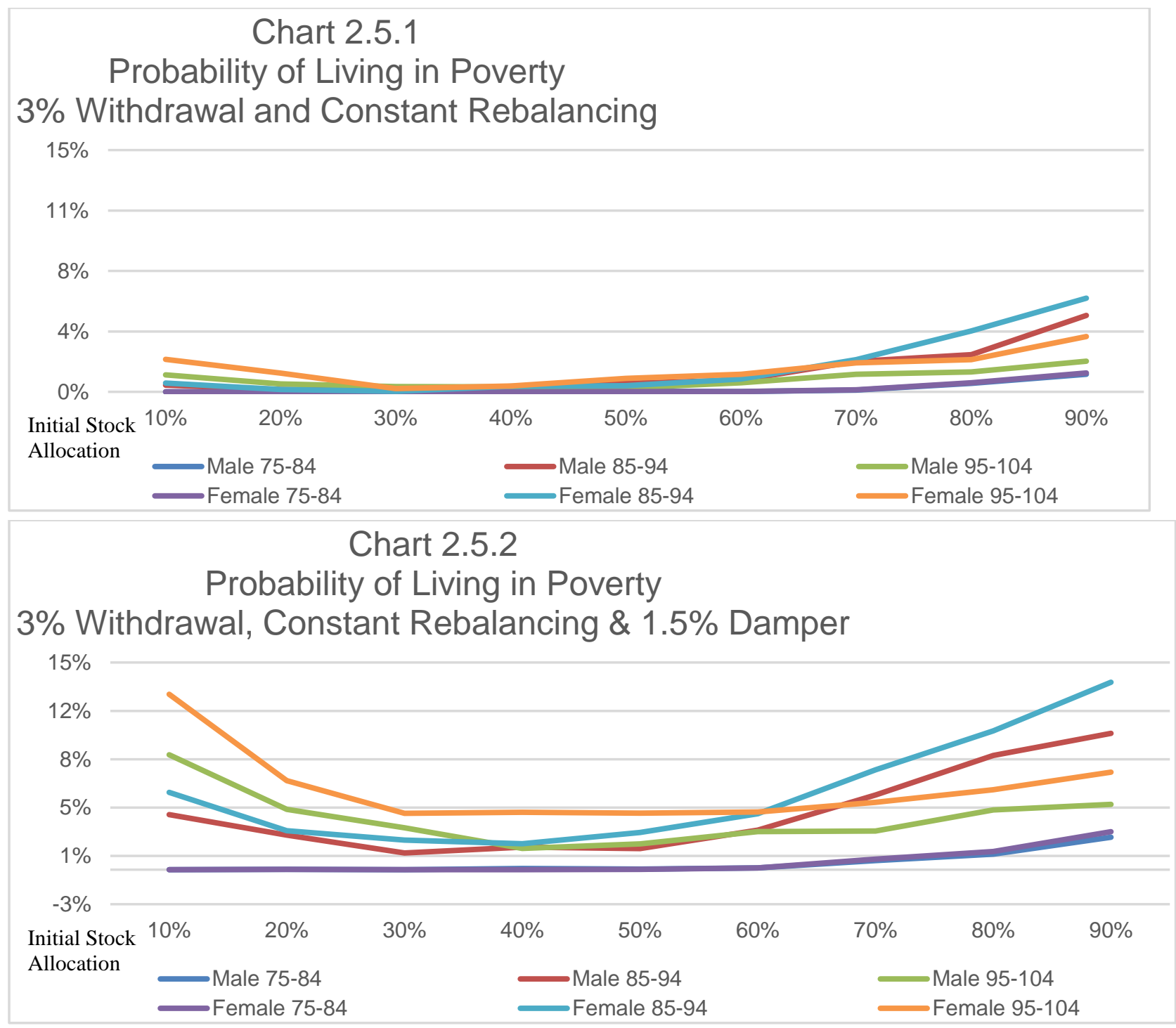

These charts demonstrate that even a relatively small decrease in investment returns from historical returns substantially increases the probability of living in financial ruin, consistent with the analysis by Finke, Pfau \& Blanchett. Amongst some age/gender groups who live in a low investment return environment, the probability of living in financial ruin can triple or quadruple.

2.6 Fortunate and Unfortunate Investors: The simulated investment returns in the model formed a probability distribution function because the historical returns of the two asset classes each formed its own probability distribution function. Chart 2.6 displays the probability distribution function formed by an initial asset allocation of $60 \%$ stocks and $40 \%$ bonds, with a $4 \%$ withdrawal rate and level rebalancing. Returns below $4.5 \%$ were more than two standard deviations below the mean investment return. These returns correspond to those retirees who were living in poverty. Despite having the same initial asset allocation, withdrawal rate and rebalancing method 
as the remainder of the 10,000 simulated retirees, these retirees exhausted their portfolio while alive. They were "unfortunate investors".

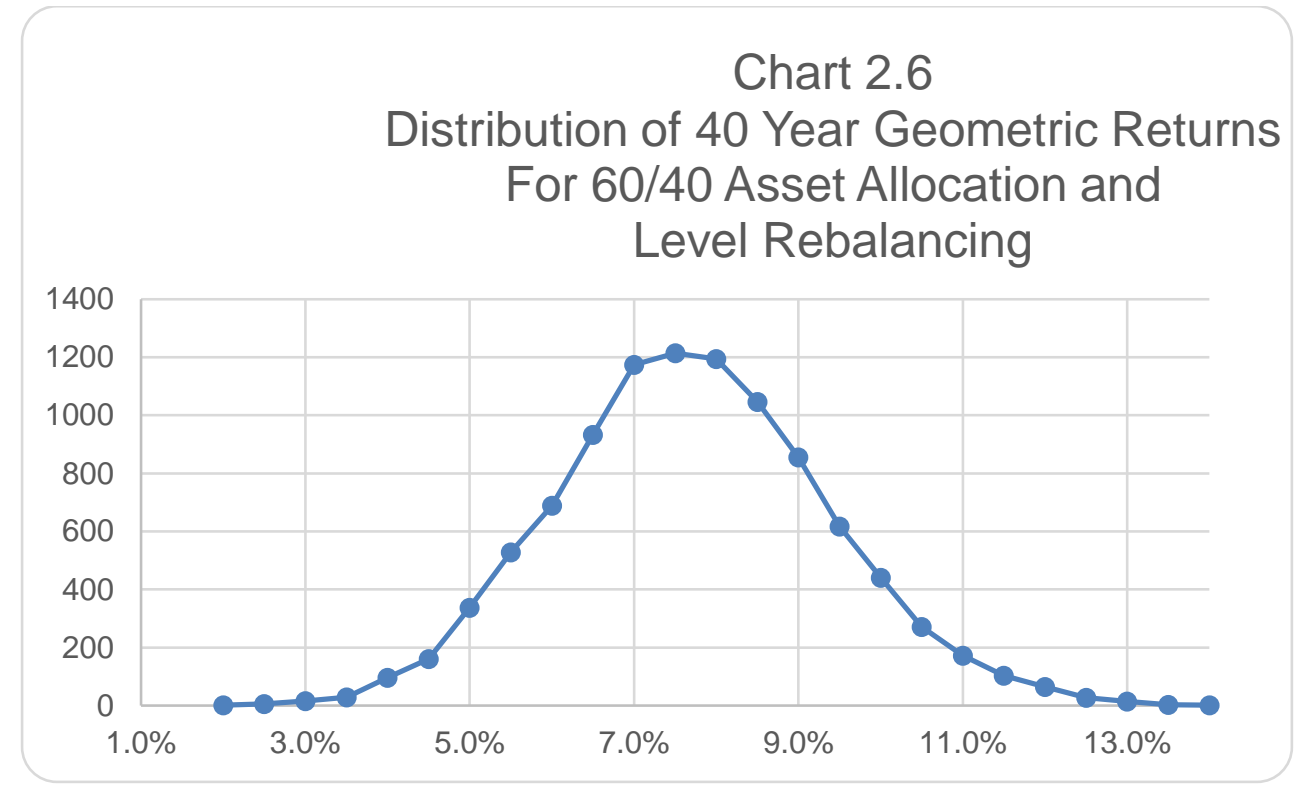

Returns above $11.25 \%$ were higher than two standard deviations above the mean investment return. These returns correspond to those retirees whose portfolios at death were several times the size of their initial portfolio. Despite having the same initial asset allocation, withdrawal rate and rebalancing method as the remainder of the 10,000 simulated retirees, these retirees actually increased their portfolio while alive. They were "fortunate investors".

"Unfortunate investors" suffered the Sequence of Return Risk, or "the risk of receiving lower or negative returns early in a period when withdrawals are made from an individual's underlying investments. The order or the sequence of investment returns is a primary concern for retirees who are living off the income and capital of their investments."xii

Two retirees with the same portfolio and withdrawal rate may have the same geometric return over a 40-year period, but one retiree may eventually be living in poverty while the other retiree may die with a portfolio larger than the initial portfolio. An example might be retirees who began withdrawing in 2010 compared to retirees who began withdrawing in 2000 . Thus, even with a relatively conservative withdrawal rate, initial asset allocation and rebalancing method, avoidance of living in poverty may depend on beginning withdrawals during a favorable investment period rather than immediately before an extended investment downturn. Of course, retirees and other investors never know when an investment downturn will begin or how long it will last. 
2.7. Limitations of the Model: This model has some limitations due to it being a one semester independent study project. For example, inflation is a significant factor in investment returns, particularly long-term bond returns, but the model does not reflect current low inflation, nor its future volatility, in any of the future investment returns. The effect of different constant levels of inflation and variable inflation will be analyzed in an extension of this paper. Also, current longterm bond returns are near historic lows, and the model ignores this when it generates bond returns in the early years of the projection.

The authors acknowledge that required minimum distribution requirements could impact the probability of living in poverty in later years. This is a topic that can also be explored in an extension of this paper.

The use of Ibbotson data for large company stocks and Treasury Bills produced a particular set of results. Using different sources of data for the historical returns or different historical periods would undoubtedly lead to different results. While this model used only two asset classes, many retirement portfolios have several asset classes, each with its own expected return and volatility. Also, there was assumed to be no correlation between these two asset classes. Using more asset classes or assuming correlation between asset classes would likely lead to different results.

The authors acknowledge that retiree spending is usually not held constant in real terms during retirement. Many retirees tend to spend more during the early years of retirement and then spending tends to level off, even considering increased health care costs later in retirement. The portfolio and initial withdrawal rates in this paper should be considered as standard of living maintenance spending, net of Social Security and defined benefit pensions, excluding any discretionary spending and any bequest motive. Retirees can satisfy those specific desires in a separate portfolio.

The authors also acknowledge that retirees who are facing imminent financial ruin might be able to reduce their withdrawal amounts by reducing their standard of living. They could maintain their standard of living by reducing their bequest objectives. Retirees could also live after exhausting their portfolio by receiving public assistance, enrolling in Medicaid, living with their children, etc. These options were part of the impetus to measure the length of time that retirees live after exhausting their portfolios. Those behavioral changes are beyond the scope of this paper.

Lastly, this paper uses a mathematical model to analyze various withdrawal strategies. The authors acknowledge that investor behavior, risk tolerance and risk aversion will affect the success of any withdrawal strategy. These behavioral economic factors are beyond the scope of this paper. 
This model is intended to illustrate the impact of withdrawal rates, gender, initial asset allocation, rebalancing methods, low investment return environments and mortality on the probability of living in poverty in retirement, and should not be used as a retirement planning tool in any specific situation.

\section{Discussion:}

This paper discovered three retirement withdrawal concepts that were not immediately obvious to the authors beforehand, as well as confirming early researchers' findings.

- A retirement portfolio's exhaustion is not a terminal event, but rather is the beginning of a retiree's living in poverty. Thus, this paper measured not only the event of financial ruin but also its duration during the retiree's remaining lifetime.

- Rebalancing the asset allocation as the retiree ages has relatively little impact on the probability of living in poverty.

- A successful retirement depends somewhat upon luck, such as a retiree beginning withdrawals during an extended favorable investment environment, rather than immediately before an economic downturn.

- An initial asset allocation of a balance between stocks and fixed income is a strong indicator of a successful retirement withdrawal strategy. This is consistent with the findings of Bengen and Finke, Pfau \& Blanchett.

- In the current low investment return environment, a successful retirement withdrawal rate is $3 \%$ or even lower, rather than $4 \%$. This is consistent with the findings of Finke, Pfau \& Blanchett.

\section{Materials and Methods:}

This section describes the assumptions and the development of an Excel model to analyze retirement withdrawal strategies using stochastic techniques.

Several assumptions are used in the model, in addition to the ones already mentioned, such as:

- Retiree (age 65) is not married, has no dependents, and does not have a bequest motive

- No correlation between asset classes

- Returns are net of investment expenses

- Inflation is constant, assuming $2.75 \%$ annual inflation

- Deaths occur at the end of the year

- Benefits are paid throughout the year 
- Portfolio is a tax-deferred vehicle, so taxes are paid when withdrawals are made

- Desired lifetime income includes taxes, and the tax rate is assumed constant

- Mandatory distribution requirements are ignored

The stochastic investment model uses two asset classes to project investment returns for 40 years:

- Large Company Stocks

\section{- $\quad$ Long Term Government Bonds}

These two asset classes model future returns using Ibbotson ${ }^{\text {xiii }}$ data from 1926 through 2009 . The historical data for the two asset classes was fitted to a pair of three parameter lognormal distributions which are used for the model's asset return projections. Commercial software identified three parameter lognormal distributions as well-fitting distributions to the underlying data according to Kolmogorov-Smirnov and Anderson-Darling criteria.

A lognormal distribution is used when the original data is positively skewed, but the natural logarithms of the original data tend to follow a normal distribution. In this distribution ${ }^{\text {xiv }}$

- $\mu$ is the scale parameter that stretch or shrink the distribution

- $\sigma$ is the shape parameter that affects the shape of the distribution and

- $\gamma$ is the threshold parameter or location parameter that defines the point where the support set of the distribution begins.

- In order to fit the data at hand, we modeled each independent identically distributed yearly asset class return $X$ via three-parameter lognormal distributions, noted as $\operatorname{TPLN}(\mu, \sigma, \gamma)$ with input from a standard normal random variable $\mathrm{Z}$ via $\mathrm{X} \sim e^{\mu+\sigma Z}+\gamma$, and whose expected value is $\mathbb{E}[X]=e^{\mu+\frac{1}{2} \sigma^{2}}+\gamma$.

- In other words, we have that $\ln (X-\gamma) \sim \mathrm{N}\left(\mu, \sigma^{2}\right)$.

- Calibration is obtained for the three parameters $(\mu, \sigma, \gamma)$ that fit the three-parameter lognormal distribution to the underlying historical returns for each asset class.

Other authors such as Richey $(2012)^{\mathrm{xv}}$ and Oppong, Asamoah, and Ofori (2016) ${ }^{\mathrm{xvi}}$, have considered the TPLN distribution to model stock returns and calibrate to empirical data.

In the simulations we used, harvesting parameters from historical data for subsequent simulation resulted in the model for large company stock returns to be defined as

$$
\begin{array}{cc}
X_{\text {LargeCompany }} & \sim \operatorname{TPLN}(6.588,0.02834,-714.18) \\
\mathbb{E}\left[X_{\text {LargeCompany }}\right] & =e^{\left(6.588+\frac{1}{2}(0.02834)^{2}\right)}-714.18=12.148
\end{array}
$$


We note that these simulated values are in percentages. Long term government bonds, calibrated to our historical data and parameters harvested, resulted in a simulation where such returns were held to follow

$$
\begin{array}{cc}
X_{\text {GovtBonds }} & \sim \operatorname{TPLN}(3.576,0.24905,-31.033) \\
\mathbb{E}\left[X_{\text {GovtBonds }}\right] & =e^{\left(3.576+\frac{1}{2}(0.24905)^{2}\right)}-31.033=5.823
\end{array}
$$

We note that these simulated values are also in percentages.

Stochastic mortality was modeled by a random number between zero and one at each age from 65 to 104. If the random number at each age exceeded the probability of death for that age, the retiree survived that year. If the random number at any age was less than or equal to the probability of death for that age, the retiree died.

The probability of death at each age from 65 to 104 was taken from the RP-2014 Mortality Table with generational improvement based on scale MP-2016.

\section{Conclusion:}

In this analysis, we have found withdrawal strategies that allow an investor, depending on their mortality, gender, and other determining parameters, to minimize their weighted probability of ruin, that is, the probability of living in poverty. The Monte-Carlo type simulation implemented here can be expanded for models that allow for greater flexibility in modeling assumptions, such as non-constant consumption rate, variable inflation, annuity purchases and so on. This will be the subject of future research.

Acknowledgements: There were no funds or grants received for this article.

Author Contributions: This paper is based on work done by Tim Blumenschein and Spencer Crough in a one semester independent study actuarial science class at Michigan State University in 2017, under the sponsorship and assistance of Dr. Albert Cohen. The author thanks them for developing the stochastic Excel investment portfolio and retiree mortality model and their suggestions on various drafts of this paper. The author also thanks anonymous reviewers whose advice greatly improved this paper.

Conflicts of Interest: The authors declare no conflict of interest.

\section{References}


i The Nation's Retirement system, GAO-18-111SP, October 2017, page 10

ii The Nation's Retirement System, GAO-18-111SP, October 2017, page 61

iii The Challenge of Longevity Risk: Making Retirement Income Last a Lifetime, October 2015, American Academy of Actuaries, Institute and Faculty of Actuaries and Actuaries Institute of Australia

iv Ibid

${ }^{v}$ Differences in Life Expectancy by Income Level, Contingencies July/August 2016, Tim Geddes and Robert J. Rietz

vi RP-2014 Mortality Tables, Society of Actuaries, Revised November 2014

vii Mortality Improvement Scale MP-2016, Society of Actuaries, 2016

viii Reclaiming the Future, Allianz Life Insurance Company of North America, 2010

ix William Bengen (October 1994) Determining Withdrawal Rates Using Historical Data, Journal of Financial Planning, 171-180

${ }^{x}$ Michael Finke, Wade Pfau \& David Blanchett (October 2013) The 4\% Rule is Not Safe in a LowYield World Journal of Financial Planning 46-55

${ }^{x i}$ Kristen S. Moore \& Virginia R. Young (2006) Optimal and Simple, Nearly Optimal Rules for Minimizing the Probability of Financial Ruin in Retirement, North American Actuarial Journal, 10:4, 145-161

xii Investopedia https://www.investopedia.com/terms/s/sequence-risk.asp

xiii 2010 Ibbotson Classic Yearbook

${ }^{\text {xiv }}$ Estimating the Parameters of the Three-Parameter Lognormal Distribution Rodrigo J. Aristizabal, Florida International University, March 30, 2012

xv Richey, Daniel Lee. "The Distribution of Individual Stock Returns in a Modified Black-scholes Option Pricing Model." (2012).

xvi Oppong, S.O., Asamoah, D., and Ofori, E. "Empirical Distributions of Stock Returns - Ghana Stock Exchange" (2016), available online from IJICTM at www.jijictm.org/admin/html/mail/attach/2016-09-14-06-23-50.pdf 